Article

\title{
Impact of the COVID-19 Pandemic on Seasonal Variations in Childhood and Adolescent Growth: Experience of Pediatric Endocrine Clinics
}

\author{
Jin-Ah Han ${ }^{1}$ (D), Yae-Eun Chung ${ }^{1}$, In-Hyuk Chung ${ }^{2}$, Yong-Hee Hong ${ }^{3}$ and Sochung Chung ${ }^{1,4, *(\mathbb{D})}$ \\ 1 Department of Pediatrics, Konkuk University Medical Center, Konkuk University School of Medicine, \\ Seoul 05030, Korea; 20190107@kuh.ac.kr (J.-A.H.); 20160090@kuh.ac.kr (Y.-E.C.) \\ 2 Department of Pediatrics, National Health Insurance Service Ilsan Hospital, Goyang 10444, Korea; \\ ped-endo@nhimc.or.kr \\ 3 Department of Pediatrics, Soonchunhyang University Bucheon Hospital, \\ Soonchunhyang University School of Medicine, Bucheon 14584, Korea; hongyonghee@schmc.ac.kr \\ 4 Research Institute of Medical Science, Konkuk University School of Medicine, Seoul 05029, Korea \\ * Correspondence: scchung@kuh.ac.kr; Tel.: +82-2-2030-7553; Fax: +82-2-2030-7748
}

check for

updates

Citation: Han, J.-A.; Chung, Y.-E.; Chung, I.-H.; Hong, Y.-H.; Chung, S. Impact of the COVID-19 Pandemic on Seasonal Variations in Childhood and Adolescent Growth: Experience of Pediatric Endocrine Clinics. Children 2021, 8, 404. https://doi.org/ 10.3390/children8050404

Academic Editors: Rhodri S. Lloyd and Tuan Nguyen

Received: 31 March 2021

Accepted: 14 May 2021

Published: 17 May 2021

Publisher's Note: MDPI stays neutral with regard to jurisdictional claims in published maps and institutional affiliations.

Copyright: (c) 2021 by the authors. Licensee MDPI, Basel, Switzerland. This article is an open access article distributed under the terms and conditions of the Creative Commons Attribution (CC BY) license (https:/ / creativecommons.org/licenses/by/ $4.0 /)$.

\begin{abstract}
Background: Children experience seasonal variations in growth whereby height increases most in spring and least in autumn, and weight increases least in spring and most in autumn. We hypothesized that activity restriction caused by efforts to contain the spread of coronavirus disease 2019 (COVID-19) would result in increased body mass index (BMI) in children, differing from conventional seasonal growth variations. Methods: We included 169 children who visited endocrine clinics of three hospitals in Korea at regular intervals under the same conditions for two years. Visit dates were D1 (January, 2019), D2 (July, 2019), D3 (January, 2020) before the COVID-19 outbreak, and D4 (July, 2020) during the pandemic. Differences in the z-score for height (HT), weight (WT), and BMI among time points and between spring seasons (i.e., S1-S3) were compared. Results: There were significant differences in BMIz among time points, which decreased from D1-D2 and increased from D2-D3 and D3-D4. WTz significantly increased from D2-D3 and D3-D4. BMIz values of S1 (spring 2019) and S3 (spring 2020) were -0.05 and 0.16 , respectively, showing significant differences. WTz values between S1 and S3 were significantly different ( -0.02 vs. 0.13$)$. Conclusions: In 2019, there were conventional seasonal variations in BMIz, which declined in spring and increased in autumn, while in 2020, BMIz increased even in spring. The COVID-19 pandemic may have affected seasonal variations in the growth of children attending endocrine clinics.
\end{abstract}

Keywords: COVID-19; children; body mass index; seasonal variation; growth

\section{Introduction}

Coronavirus disease 2019 (COVID-19), caused by a new coronavirus called severe acute respiratory syndrome coronavirus 2 (SARS-CoV-2), is prevalent worldwide, and the World Health Organization (WHO) first learned of this new virus on 31 December 2019 and declared the novel coronavirus (COVID-19) outbreak a global pandemic on 11 March 2020 [1,2]. According to the WHO announcement on 6 December 2020, the cumulative number of confirmed cases worldwide is approximately 66 million, and the cumulative death toll is approximately 1.5 million [3]. As of 10 December 2020, more than 50 vaccines are in clinical trial stages worldwide, and Pfizer vaccination administration has already begun as of 8 December in the United Kingdom [4]. However, it will take a long time to reach population immunity by vaccination, and sufficient vaccine quantities have not yet been supplied to the world. Accordingly, COVID-19 is expected to continue to be prevalent in many countries for the foreseeable future.

In addition to vaccination, many countries, including Korea, are making efforts to prevent its spread. These measures include making it mandatory to wear a mask in indoor 
and outdoor public places, closing schools and replacing them with online classes, and restricting the use of stores and sports centers [5]. As a result of these measures, the activities of most people, including children, have been restricted [6,7].

Season and time of year are among the environmental factors that influence the growth and development of children and adolescents [8-16]. There are seasonal variations in growth, in that height increases most in spring and least in autumn, and weight increases least in spring and most in autumn [8-11]. In a recent cross-sectional study, there was a rapid decrease in BMI z-scores from May to June and a rapid increase between August and September [13]. Body mass index (BMI) in children is known to increase more during vacation periods than school semesters $[17,18]$. One of the reasons for this is decreased physical activity during the vacation [17]. Concerns about weight gain have increased after the COVID-19 outbreak, along with decreased physical activity and the restriction of outdoor activity, in the era of an obesity epidemic.

We conducted this study to confirm whether activity restriction caused by efforts to contain the spread of COVID-19 may cause weight gain and result in increased BMI in children and adolescents, and to determine whether there was a different seasonal variation after the COVID-19 outbreak in children who visited endocrine clinics.

\section{Materials and Methods}

\subsection{Subjects}

This study included 169 children and adolescents (40 males, 129 females) who visited pediatric endocrine clinics of three hospitals (Konkuk University Medical Center, National Health Insurance Service Ilsan Hospital, Soonchunhyang University Bucheon Hospital) in Korea at regular intervals between January 2019 and July 2020.

Most of the participants were children who visited the outpatient clinic for monitoring of growth and puberty. The reasons for visits were categorized into monitoring of growth $(18.3 \%)$ or pubertal development $(23.7 \%)$, the diagnosis of early or precocious puberty $(41.4 \%)$, growth hormone deficiency $(7.1 \%)$, or other endocrine disorders $(9.5 \%)$ such as congenital hypothyroidism on levothyroxine with stable euthyroid state. In addition, patients receiving a gonadotropin-releasing hormone $(\mathrm{GnRH})$ agonist for precocious puberty were included in the study.

Patients who had the same treatment for their individual disease for the study duration were included, and patients whose treatments changed were excluded. The study protocol was approved by the institutional review board of Konkuk University Medical Center (file No.: 2020-12-008).

\subsection{Anthropometric Measurements}

Height and weight were measured in light clothing without shoes. Height was measured with a stadiometer (SECA 225, SECA Deutschland, Hamburg, Germany) to the nearest $0.1 \mathrm{~cm}$, and weight was measured with a digital scale (GL-6000-20, CASKOREA, Seoul, Korea) to the nearest $0.1 \mathrm{~kg}$. BMI was calculated as weight in kilograms divided by height in meters squared. Height (HT), weight (WT), and BMI z-scores were calculated with the LMS method by age and sex, using the 2017 Korean National Growth Charts for children and adolescents [19].

The dates of visits (D) on which the anthropometric measurements were taken were D1 (January, 2019), D2 (July, 2019), D3 (January, 2020) before the COVID-19 outbreak, and D4 (July, 2020) after the peak of the outbreak, for a total of four visits. In addition, we also calculated the season (S), which is the change in growth value for each visit point. A schematic diagram of D (date of visit) and S (season) is shown in Figure 1. We defined the spring season as from January to July, and the fall season from July to January of the following year, with the study divided into three seasons (i.e., S1, S2, and S3).

Thereafter, differences in the z-score of height, weight, and BMI among the time points (i.e., D1-D2, D2-D3, and D3-D4) and between spring 2019 and spring 2020 (i.e., S1-S3) were compared and analyzed. 


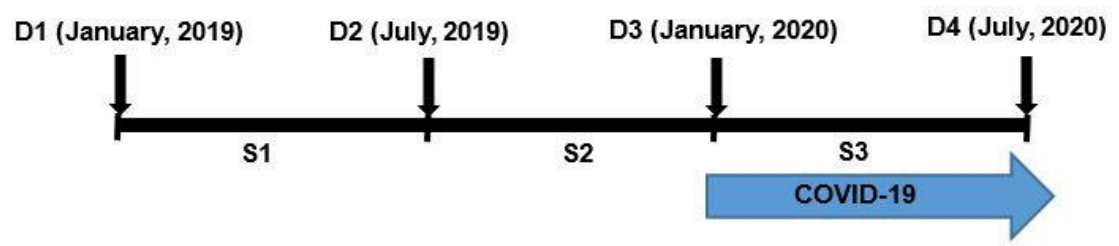

Figure 1. Schematic diagram of the dates of visits (D) and seasons (S).

\subsection{Statistical Analysis}

Each result was expressed as the mean \pm standard deviation. The z-scores for height, weight, BMI per visit date (D), and season (S) were compared and analyzed using a paired $t$-test. All analyses were performed using SPSS ver. 17.0 (SPSS Inc., Chicago, IL, USA), and $p$-values of less than 0.05 were considered significant.

\section{Results}

A total of 169 children were included for analysis. The demographic data of the study group by sex at the first visit (D1) are summarized in Table 1. The mean age was $11.14 \pm 2.44$ years and $9.56 \pm 2.07$ years for boys and girls, respectively, and the mean overall age was $9.93 \pm 2.26$ years. The mean BMI was $19.04 \pm 2.84 \mathrm{~kg} / \mathrm{m}^{2}$, and the mean BMIz was $0.41 \pm 1.01 \mathrm{~kg} / \mathrm{m}^{2}$ for all participants.

Table 1. The characteristics of the study populations at the first visit (D1).

\begin{tabular}{cccc}
\hline & Male $(\mathbf{n}=\mathbf{4 0})$ & Female $(\mathbf{n}=\mathbf{1 2 9})$ & Total $(\mathbf{n}=\mathbf{1 6 9 )}$ \\
\hline Age $(\mathrm{yr})$ & $11.1 \pm 2.4$ & $9.6 \pm 2.1$ & $9.9 \pm 2.3$. \\
HT $(\mathrm{cm})$ & $144.2 \pm 17.4$ & $138.3 \pm 9.9$ & $139.7 \pm 12.3$ \\
WT $(\mathrm{kg})$ & $43.2 \pm 16.1$ & $36.4 \pm 8.8$ & $38.0 \pm 11.3$ \\
BMI $\left(\mathrm{kg} / \mathrm{m}^{2}\right)$ & $20.0 \pm 3.6$ & $18.8 \pm 2.5$ & $19.0 \pm 2.8$ \\
HTz & $-0.35 \pm 1.25$ & $0.58 \pm 1.14$ & $0.36 \pm 1.23$ \\
WTz & $-0.03 \pm 1.32$ & $0.61 \pm 0.97$ & $0.46 \pm 1.09$ \\
BMIz & $0.22 \pm 1.17$ & $0.47 \pm 0.95$ & $0.41 \pm 1.01$ \\
\hline
\end{tabular}

Values are presented as means \pm standard deviations. HT, height; WT, weight; BMI, body mass index; HTz, height z-score; WTz, weight z-score; BMIz, body mass index z-score.

The comparisons of z-scores for height, weight, and BMI among the visit dates are shown in Figure 2 and Table 2. The averages of HTz, WTz, and BMIz at each visit date (D) are shown in the form of a line graph in Figure 2. In this graph, the solid line indicates that the values among the time points were significantly different $(p<0.05)$, and the dotted line indicates that the difference was not significant $(p>0.05)$. HTz significantly increased across visit dates in boys, but there was no significant difference between any visit dates for the cohort overall. With regard to WTz and BMIz changes, they were not significantly different between D1 and D2 in boys, but increased significantly between D2 and D3 and between D3 and D4. In girls, WTz and BMIz significantly decreased between D1 and D2, and significantly increased between D2 and D3 and between D3 and D4. For the study cohort, the averages of BMIz in D1 and D2 were $0.41 \pm 1.01$ and $0.37 \pm 1.04$, and BMIz significantly decreased from D1 to D2 $(p=0.047)$, as shown in Figure 2 and Table 2 . The means of BMIz in D2, D3, and D4 were $0.37 \pm 1.04,0.53 \pm 1.03$, and $0.68 \pm 1.12$, respectively, and there were significant increases observed from D2-D3 and D3-D4 $(p<0.001)$.

The comparisons of z-scores between the spring seasons (S1, spring 2019 vs. S3, spring 2020) are shown in Table 3. For the total study cohort, no significant difference was observed between $\mathrm{S} 1$ and $\mathrm{S} 3$ for $\mathrm{HTz}$, but the means of WTz were significantly different between S1 and S3 $(p<0.001)$, at $-0.02 \pm 0.24$ and $0.13 \pm 0.28$, respectively. The averages of BMIz in S1 and S3 were $-0.05 \pm 0.30$ and $0.16 \pm 0.34$, respectively, for which the difference was statistically significant $(p<0.001)$. 

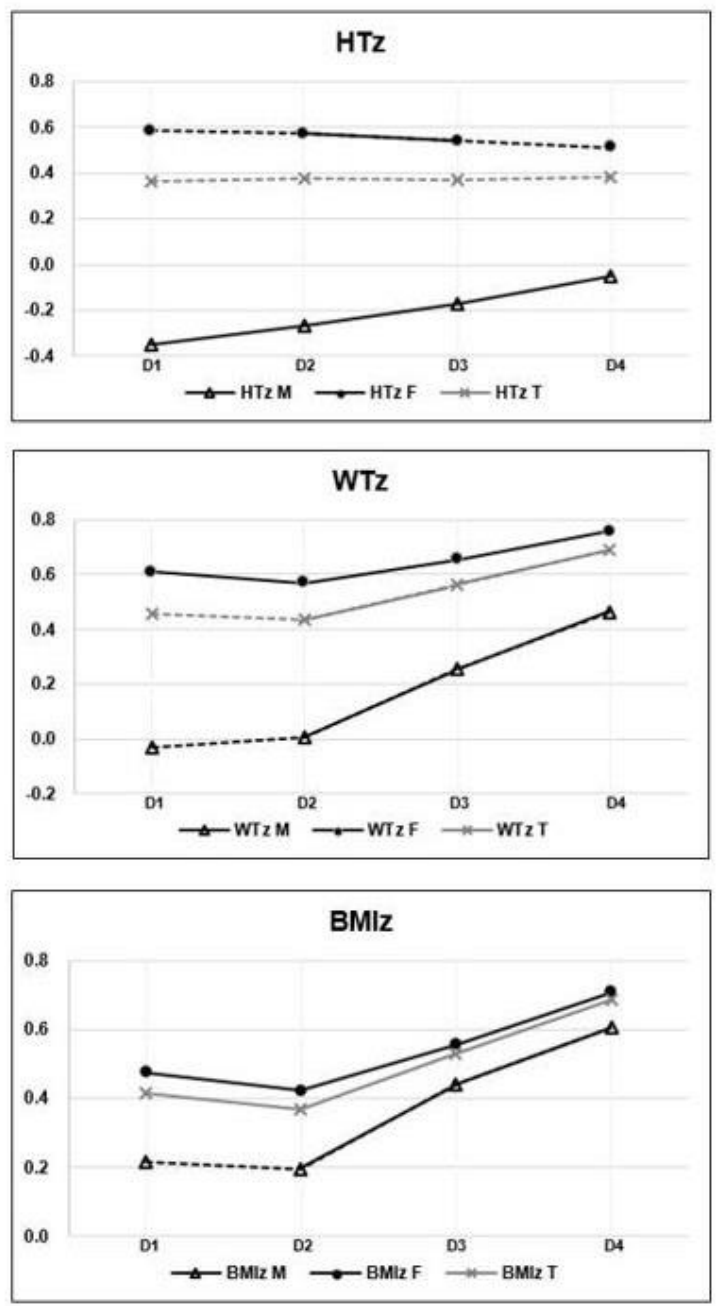

Figure 2. Z-scores of height (HT), weight (WT), and body mass index (BMI) at each visit date (D). D, date of visit; M, male; F, female; T, total; HTz, height z-score; WTz, weight z-score; BMIz, body mass index z-score. The solid line indicates that the difference in the value among the dates of visits is statistically significant, and the dotted line indicates non-significant differences.

Table 2. The comparisons of z-scores among the visit dates (D).

\begin{tabular}{cccccc}
\hline & & D1 & D2 & D3 & D4 \\
\hline \multirow{3}{*}{ HTz } & $M^{\mathrm{abc}}$ & $-0.35 \pm 1.25$ & $-0.27 \pm 1.24$ & $-0.17 \pm 1.12$ & $-0.05 \pm 1.09$ \\
& $\mathrm{~F}^{\mathrm{b}}$ & $0.58 \pm 1.14$ & $0.57 \pm 1.10$ & $0.54 \pm 1.08$ & $0.51 \pm 1.06$ \\
& $\mathrm{~T}^{\mathrm{T}}$ & $0.36 \pm 1.23$ & $0.37 \pm 1.18$ & $0.37 \pm 1.13$ & $0.38 \pm 1.09$ \\
\hline \multirow{3}{*}{ WTz } & $\mathrm{M}^{\mathrm{bc}}$ & $-0.03 \pm 1.32$ & $0.01 \pm 1.31$ & $0.26 \pm 1.29$ & $0.46 \pm 1.40$ \\
& $\mathrm{~F}^{\mathrm{abc}}$ & $0.61 \pm 0.97$ & $0.57 \pm 1.00$ & $0.65 \pm 0.99$ & $0.76 \pm 1.02$ \\
& $\mathrm{~T}^{\mathrm{bc}}$ & $0.46 \pm 1.09$ & $0.44 \pm 1.10$ & $0.56 \pm 1.08$ & $0.69 \pm 1.12$ \\
\hline \multirow{3}{*}{ BMIz } & $\mathrm{M}^{\mathrm{bc}}$ & $0.22 \pm 1.17$ & $0.19 \pm 1.16$ & $0.44 \pm 1.21$ & $0.61 \pm 1.36$ \\
& $\mathrm{~F}^{\mathrm{abc}}$ & $0.47 \pm 0.95$ & $0.42 \pm 1.00$ & $0.56 \pm 0.98$ & $0.71 \pm 1.04$ \\
& $\mathrm{~T}^{\mathrm{abc}}$ & $0.41 \pm 1.01$ & $0.37 \pm 1.04$ & $0.53 \pm 1.03$ & $0.68 \pm 1.12$
\end{tabular}

Values are presented as means \pm standard deviations. D, date of visit; $\mathrm{M}$, male; F, female; T, total; HTz, height z-score; WTz, weight z-score; BMIz, body mass index z-score. The $p$-value of the difference among the visit dates was calculated using a paired $t$-test. ${ }^{\mathrm{a}}: p$-value was statistically significant $(<0.05)$ between $\mathrm{D} 1$ and $\mathrm{D} 2,{ }^{\mathrm{b}}: p$-value was statistically significant $(<0.05)$ between D2 and D3, ${ }^{c}: p$-value was statistically significant $(<0.05)$ between D3 and D4. 
Table 3. The comparisons of z-scores by spring season (S1 (2019 spring) vs. S3 (2020 spring)) using paired $t$-test.

\begin{tabular}{ccccc}
\hline & & S1 & S3 & $p$ Value \\
\hline \multirow{3}{*}{ HTz } & Male & $0.08 \pm 0.19$ & $0.12 \pm 0.23$ & 0.236 \\
& Female & $-0.01 \pm 0.17$ & $-0.03 \pm 0.18$ & 0.350 \\
& Total & $0.01 \pm 0.18$ & $0.01 \pm 0.20$ & 0.882 \\
\hline \multirow{2}{*}{ WTz } & Male & $0.04 \pm 0.27$ & $0.20 \pm 0.35$ & 0.025 \\
& Female & $-0.04 \pm 0.23$ & $0.10 \pm 0.25$ & $<0.001$ \\
& Total & $-0.02 \pm 0.24$ & $0.13 \pm 0.28$ & $<0.001$ \\
\hline \multirow{2}{*}{ BMIz } & Male & $-0.02 \pm 0.31$ & $0.17 \pm 0.42$ & 0.027 \\
& Female & $-0.05 \pm 0.29$ & $0.15 \pm 0.32$ & $<0.001$ \\
& Total & $-0.05 \pm 0.30$ & $0.16 \pm 0.34$ & $<0.001$
\end{tabular}

Values are presented as means \pm standard deviations. HTz, height z-score; WTz, weight z-score; BMIz, body mass index $z$-score; $S$, season; $S(n) z$-score $=(D(n+1) z$-score $)-(D(n) z$-score $)$. The $p$-value of the difference between $\mathrm{S} 1$ and $\mathrm{S} 3$ was calculated using a paired $t$-test.

\section{Discussion}

The worldwide impact of the COVID-19 pandemic has continued for more than a year, and negative health effects secondary to restrictions may be exacerbated. In this study, we hypothesized that activity restriction as a result of efforts to prevent the spread of COVID-19 would result in more weight gain and higher BMI, leading to a difference in growth from the conventional seasonal variations in children.

The strength of this study is that the data collected were reliably measured directly by medical institutions. We confirmed the existence of conventional seasonal variation in growth before the COVID-19 pandemic and different patterns after the COVID-19 outbreak by comparing and analyzing the data obtained before and after the COVID-19 outbreak in children attending endocrine clinics.

Although some studies have suggested and reported increased weight and BMI secondary to the COVID-19 pandemic, these studies were conducted in the form of questionnaires instead of measuring weight and height; thus, the studies may have been affected by bias and low reliability $[7,20-22]$.

A previous study predicted the impact of the COVID-19 pandemic on childhood obesity using a microsimulation model [23]. The predicted increase in the BMIz in scenarios 1 to 4 were $0.056,0.084,0.141$, and 0.198, respectively. Increased BMIz in S3 in our study was 0.16 , which is comparable to scenarios 1 to 4 . Considering that our study ended in July 2020, it can be seen that the impact of the COVID-19 pandemic is greater than expected, with a value greater than 0.141 in scenario 3 .

As shown in Figure 2 and Table 2, in the total study cohort, there were significant differences in BMIz among the time points, decreasing in D1-D2 and increasing from both D2-D3 and D3-D4. This suggests that in 2019, there were seasonal variations in BMIz, which declined in spring and increased in autumn, as in previous studies [8-11]. Meanwhile, in 2020, after the peak of the COVID-19 outbreak, BMIz increased even in spring, contrary to the typical seasonal variation.

In addition, there were significant differences $(p<0.001)$ between S1 (2019 spring) and S3 (2020 spring) in WTz and BMIz in the overall cohort, as shown in Table 3. In S1, the means of WTz and BMIz were -0.02 and -0.05 , respectively, compared to those of S3 at 0.13 and 0.16 , respectively. That is, WTz and BMIz decreased in the spring season before the COVID-19 outbreak, but increased in the spring season after the peak of the outbreak. These results suggest that the COVID-19 pandemic affected the seasonal variations in this population.

This study had several limitations. First, this study was conducted under the assumption that physical activity would have decreased due to the COVID-19 outbreak. However, there is no analysis of physical activity before and after the COVID-19 outbreak; thus, the 
causal relationship may not be clear. Second, our study period was not long enough and only the first half of the year after the start of the COVID-19 pandemic was investigated.

Third, the sample may not be fully representative, as the sample size was small, and only children who visited the pediatric endocrine outpatient clinics, including for growth and puberty monitoring, were included. The incidence and prevalence of central precocious puberty (CPP) in Korea have increased steeply in recent years, especially in girls $[24,25]$. According to a study investigating the incidence and prevalence of CPP from 2008 to 2014, the incidence and prevalence of CPP was two to three times higher than those of a Danish study investigating the period from 1993 to $2001[25,26]$.

Most $(90.5 \%)$ of the subjects in this study visited an outpatient clinic for the evaluation of growth and puberty development, including those treated for growth hormone deficiency and CPP, and girls accounted for the majority (76.5\%) of the population. Forty percent of boys visited for growth monitoring, while $77.5 \%$ of girls for pubertal development owing to a concern of early or precocious puberty. Since there were no changes in or discontinuations of treatment during the study period, including these patients did not have an effect on the results of this study.

The high interest in growth and puberty could be a socio-cultural characteristic among Koreans. Thirty years ago, type 2 diabetes in children was considered rare [27]. However, the obesity epidemic has led to a dramatic increase in the numbers of youth with obesityrelated disorders all over the world, including Korea [28-30]. Rising rates of obesity-related disorders in Korean children have attracted the attention and concerns of parents and society. The rate of dyslipidemia in obese Korean adolescents is high and has been reported as $56.1 \%$, and the 2017 clinical practice guidelines for dyslipidemia of Korean children and adolescents have been published [29,31]. Limited studies are available to define the risks of obesity-related comorbidities in Korean children and more studies are needed [32,33].

Weight gain after the COVID-19 pandemic may be due to a decrease in physical activity, and other factors, such as increased sedentary behavior or increased access to unhealthy foods, may also have contributed. It is already known that children's weight and BMI increase more during vacation periods compared to during school semesters $[17,18]$. One of the reasons for weight gain during vacations is a decrease in physical activity [17]. Therefore, through this study, it is possible that COVID-19-related activity restriction may cause weight gain in children and adolescents attending endocrine clinics that differs from typical seasonal variations. Nonetheless, for a clearer causal relationship, a quantitative analysis of physical activity before and after COVID-19 is needed.

\section{Conclusions}

In 2019, there were seasonal variations in BMIz, which declined in spring and increased in autumn, while, in 2020 during the COVID-19 pandemic, BMIz increased even in spring. Our data suggest that the COVID-19 pandemic may have affected the seasonal variations in growth in this population. Further investigation is required to elucidate the long-term effects of the COVID-19 pandemic on growth in children.

Author Contributions: S.C. designed the study. Y.-E.C., S.C., I.-H.C. and Y.-H.H. collected the data. S.C. and J.-A.H. analyzed the data. J.-A.H., Y.-H.H. and S.C. drafted and revised the manuscript. All authors have read and agreed to the published version of the manuscript.

Funding: This research received no external funding.

Institutional Review Board Statement: The study protocol was approved by the institutional review board of Konkuk University Medical Center (file No.: 2020-12-008).

Informed Consent Statement: Patient written informed consent was waived due to the study's retrospective design.

Data Availability Statement: The data presented in this study are available on request from the corresponding author. The data are not publicly available due to personal medical data. 
Acknowledgments: The results of this study were presented at the 70th Conference of the Korean Pediatric Society in October 2020 and at the Korean Society of Pediatric Endocrinology Specialist Training Course in November 2020.

Conflicts of Interest: The authors declare no conflict of interest.

\section{References}

1. WHO. Coronavirus Disease (COVID-19). Available online: https://www.who.int/emergencies/diseases/novel-coronavirus-20 19/question-and-answers-hub/q-a-detail/coronavirus-disease-covid-19 (accessed on 30 March 2021).

2. Cucinotta, D.; Vanelli, M. WHO Declares COVID-19 a Pandemic. Acta Bio Medica Atenei Parmensis 2020, 91, 157-160. [CrossRef] [PubMed]

3. WHO. COVID-19 Weekly Epidemiological Update. Available online: https://www.who.int/publications/m/item/weeklyepidemiological-update-8-december-2020 (accessed on 8 December 2020).

4. WHO. DRAFT Landscape of COVID-19 Candidate Vaccines. Available online: https://www.who.int/publications/m/item/ draft-landscape-of-covid-19-candidate-vaccines (accessed on 10 December 2020).

5. Viner, R.M.; Russell, S.J.; Croker, H.; Packer, J.; Ward, J.; Stansfield, C.; Mytton, O.; Bonell, C.; Booy, R. School closure and management practices during coronavirus outbreaks including COVID-19: A rapid systematic review. Lancet Child Adolesc. Health 2020, 4, 397-404. [CrossRef]

6. Pietrobelli, A.; Pecoraro, L.; Ferruzzi, A.; Heo, M.; Faith, M.; Zoller, T.; Antoniazzi, F.; Piacentini, G.; Fearnbach, S.N.; Heymsfield, S.B. Effects of COVID-19 Lockdown on Lifestyle Behaviors in Children with Obesity Living in Verona, Italy: A Longitudinal Study. Obesity 2020, 28, 1382-1385. [CrossRef] [PubMed]

7. He, M.; Xian, Y.; Lv, X.; He, J.; Ren, Y. Changes in Body Weight, Physical Activity, and Lifestyle During the Semi-lockdown Period After the Outbreak of COVID-19 in China: An Online Survey. Disaster Med. Public Health Prep. 2020, 1-6. [CrossRef]

8. Takahashi, E. Growth and environmental factors in Japan. Hum. Biol. 1966, 38, 112-130. [PubMed]

9. Orr, J.; Clark, M. A Report on Seasonal Variation in the Growth of School-Children. Lancet 1930, 216, 365-367. [CrossRef]

10. Reynolds, E.L.; Sontag, L.W. Seasonal variations in weight, height, and appearance of ossification centers. J. Pediatrics 1944, 24, 524-535. [CrossRef]

11. Hong, C. Hong Changeui Pediatrics, 12th ed.; Mi Rae N: Seoul, Korea, 2020; Volume 1, p. 10.

12. Dalskov, S.M.; Ritz, C.; Larnkjaer, A.; Damsgaard, C.T.; Petersen, R.A.; Sorensen, L.B.; Hjorth, M.F.; Ong, K.K.; Astrup, A.; Molgaard, C.; et al. Seasonal variations in growth and body composition of 8-11-y-old Danish children. Pediatric Res. 2016, 79, 358-363. [CrossRef]

13. Bhutani, S.; Hanrahan, L.P.; VanWormer, J.; Schoeller, D.A. Circannual variation in relative weight of children 5 to 16 years of age. Pediatric Obes. 2018, 13, 399-405. [CrossRef]

14. VanWormer, J.J.; Kieke, B.A.; Hanrahan, L.P.; Pomeroy, J.J.; Mundy, A.; Schoeller, D.A. Circannual growth in Wisconsin children and adolescents: Identifying optimal periods of obesity prevention. Pediatric Obes. 2020, 15, e12572. [CrossRef]

15. Kobayashi, M.; Kobayashi, M. The relationship between obesity and seasonal variation in body weight among elementary school children in Tokyo. Econ. Hum. Biol. 2006, 4, 253-261. [CrossRef] [PubMed]

16. Moreno, J.P.; Johnston, C.A.; Chen, T.A.; O'Connor, T.A.; Hughes, S.O.; Baranowski, J.; Woehler, D.; Baranowski, T. Seasonal variability in weight change during elementary school. Obesity 2015, 23, 422-428. [CrossRef] [PubMed]

17. Franckle, R.; Adler, R.; Davison, K. Peer reviewed: Accelerated weight gain among children during summer versus school year and related racial/ethnic disparities: A systematic review. Prev. Chronic Dis. 2014, 11, E101. [CrossRef]

18. Von Hippel, P.T.; Powell, B.; Downey, D.B.; Rowland, N.J. The effect of school on overweight in childhood: Gain in body mass index during the school year and during summer vacation. Am. J. Public Health 2007, 97, 696-702. [CrossRef] [PubMed]

19. Kim, J.H.; Yun, S.; Hwang, S.S.; Shim, J.O.; Chae, H.W.; Lee, Y.J.; Lee, J.H.; Kim, S.C.; Lim, D.; Yang, S.W.; et al. The 2017 Korean National Growth Charts for children and adolescents: Development, improvement, and prospects. Korean J. Pediatr. 2018, 61, 135-149. [CrossRef] [PubMed]

20. Rundle, A.G.; Park, Y.; Herbstman, J.B.; Kinsey, E.W.; Wang, Y.C. COVID-19-Related School Closings and Risk of Weight Gain Among Children. Obesity 2020, 28, 1008-1009. [CrossRef]

21. Zachary, Z.; Forbes, B.; Lopez, B.; Pedersen, G.; Welty, J.; Deyo, A.; Kerekes, M. Self-quarantine and weight gain related risk factors during the COVID-19 pandemic. Obes. Res. Clin. Pract. 2020, 14, 210-216. [CrossRef] [PubMed]

22. Pellegrini, M.; Ponzo, V.; Rosato, R.; Scumaci, E.; Goitre, I.; Benso, A.; Belcastro, S.; Crespi, C.; De Michieli, F.; Ghigo, E.; et al. Changes in Weight and Nutritional Habits in Adults with Obesity during the "Lockdown" Period Caused by the COVID-19 Virus Emergency. Nutrients 2020, 12, 2016. [CrossRef] [PubMed]

23. An, R. Projecting the impact of the coronavirus disease-2019 pandemic on childhood obesity in the United States: A microsimulation model. J. Sport Health Sci. 2020, 9, 302-312. [CrossRef]

24. Kim, S.H.; Huh, K.; Won, S.; Lee, K.-W.; Park, M.-J. A significant increase in the incidence of central precocious puberty among Korean girls from 2004 to 2010. PLoS ONE 2015, 10, e0141844. [CrossRef]

25. Kim, Y.J.; Kwon, A.; Jung, M.K.; Kim, K.E.; Suh, J.; Chae, H.W.; Kim, D.H.; Ha, S.; Seo, G.H.; Kim, H.-S. Incidence and prevalence of central precocious puberty in Korea: An epidemiologic study based on a national database. J. Pediatrics 2019, 208, 221-228. [CrossRef] [PubMed] 
26. Teilmann, G.; Pedersen, C.B.; Jensen, T.K.; Skakkebæk, N.E.; Juul, A. Prevalence and incidence of precocious pubertal development in Denmark: An epidemiologic study based on national registries. Pediatrics 2005, 116, 1323-1328. [CrossRef] [PubMed]

27. Libman, I.; Arslanian, S.A. Type II diabetes mellitus: No longer just adults. Pediatric Ann. 1999, 28, 589-593. [CrossRef] [PubMed]

28. Arslanian, S.; Bacha, F.; Grey, M.; Marcus, M.D.; White, N.H.; Zeitler, P. Evaluation and management of youth-onset type 2 diabetes: A position statement by the American Diabetes Association. Diabetes Care 2018, 41, 2648-2668. [CrossRef]

29. Lim, J.S.; Kim, E.Y.; Kim, J.H.; Yoo, J.-H.; Yi, K.H.; Chae, H.W.; Choi, J.-H.; Kim, J.Y.; Hwang, I.T. 2017 Clinical practice guidelines for dyslipidemia of Korean children and adolescents. Ann. Pediatric Endocrinol. Metab. 2020, 25, 199. [CrossRef]

30. Yoon, G.H. Obesity and Types Diabetes Mellitus. J. Korean Soc. Pediatric Endocrinol. 2002, 7, 150-153.

31. Kim, S.H.; Ahn, B.C.; Joung, H.; Park, M.J. Lipid Profiles and Prevalence of Dyslipidemia in Korean Adolescents. Endocrinol. Metab. 2012, 27, 208-216. [CrossRef]

32. Lee, S.H.; Ahn, M.B.; Choi, Y.J.; Kim, S.K.; Kim, S.H.; Cho, W.K.; Cho, K.S.; Suh, B.-K.; Jung, M.H. Comparison of different criteria for the definition of insulin resistance and its relationship to metabolic risk in children and adolescents. Ann. Pediatric Endocrinol. Metab. 2020, 25, 227. [CrossRef]

33. Chu, S.-Y.; Jung, J.-H.; Park, M.-J.; Kim, S.-H. Risk assessment of metabolic syndrome in adolescents using the triglyceride/highdensity lipoprotein cholesterol ratio and the total cholesterol/high-density lipoprotein cholesterol ratio. Ann. Pediatric Endocrinol. Metab. 2019, 24, 41. [CrossRef] 